\title{
Economics of Potato Production in Northern Hills of Chhattisgarh
}

\author{
Ashwin Kumar Sinha* and Sunil Kumar Singh \\ Department of Agricultural Economics, Indira Gandhi Krishi Vishwavidyalaya, Raipur, Chhattisgarh, India \\ *Corresponding author: ashwin94sinha@gmail.com
}

\begin{abstract}
Potato plays a very significant role in the agriculture economy. It is most important tuber crop in Chhattisgarh. The present study was conducted in Northern hills zone of Chhattisgarh. Two districts were selected and one block from each selected districts was selected. Further, clusters of villages from each selected block were selected and finally, a sample of 100 potato growers comprising 40 marginal, 32 small, 17 medium and 11 large farmers were selected with the help of probability proportion criteria from selected villages. Tabular analysis was used to achieve the objectives. The study revealed that the overall cost of potato cultivation was ₹ 47408.91/ha. The major cost component was labour cost. The cost of producing one quintal of potato was ₹ 625.56. It was also observed that cost of cultivation, cost of production, gross returns, net returns, yield and marketed surplus of potato was increasing with the increases in the size of holdings land. The gross returns and net returns from potato cultivation were found to be ₹ 92766.74 and ₹ 45357.83, respectively. The overall input-output ratio was 1:1.96. The overall yield of potato was $75.71 \mathrm{qtl}$./hectare. Out of this, 97.37 per cent was marketed surplus. Majority of potato was marketed through wholesaler followed by retailer, village trader and only about one per cent was marketed through consumer directly.
\end{abstract}

Keywords: Costs, Returns, Potato, Profitability, Marketed Surplus

Potato (Solanum tuberosum L.) is one of the most important cash and tuber crops in both sub-tropical and temperate climate of the world including India. Tuber crops play an important role in food and nutritional security apart from generating income, employment and livelihood opportunities. One of the reasons for its worldwide popularity is that potatoes can be grown under a wide range of environments. Another, it has a high nutritional value (Woolfe, 1987) and produces more quickly and more nutritious food, on less land, and in harsher climates than any other major crops (FAO, 2008). The total world production of potato in 2014 was 381.68 million tonnes with an area of 1.91 million ha (FAO, 2014). India is the second largest producer of potato in the world after China and both the countries put together contribute nearly one third of the global potato production (Scott and Suarez, 2012). The area and production of potato in the country is estimated around 20,85,000 ha. and 48.09 million tonnes respectively (NHRDF, 2016). Potatoes grow well from sea level to 14,000 feet on a wider variety of soils, under a wider range of climatic conditions, than any other staple food. The potato crop matures faster that is, in 90 to 120 days, and will provide small but edible tubers in just 60 days. All in all, the potato is about the world's most efficient means of converting plant, land, water and labour into a palatable and nutritious food (Sahadevan, 2007). In the past, various researchers had studies economic analysis of potato production covering various part of India (Peer et al. 2013; Durgawati et al. 2005; Rajput et al. 2003; Lal and Sharma 2006). In potato cultivation, expenditure on seed, labour and manure and fertilizer are the major contributors of total cost of cultivation. (Noonari et al. 2016; Peer et al. 2013; Lal and Sharma 2006). Potato is a profitable enterprise inspite of high 
capital requirement (Verma and Rajput, 2002). In Chhattisgarh, potato is considered as an important cash crop. It is mainly cultivated in some parts of Surguja, Balrampur, Bilaspur, Bastar, Jashpur and Raipur districts with a total area of $41,264.00$ ha and production of 0.58 million tonnes with an average productivity of $14.26 \mathrm{t} / \mathrm{ha}$. In the state, it is grown in Rabi season except in Mainpat and Samripat hills, where it is grown in both Kharif and Rabi season. Surguja district has the largest area with 5,800 ha and production of 0.08 million tonnes with an average productivity of $15.45 \mathrm{t} / \mathrm{ha}$. (Department of Horticulture Government of Chhattisgarh Raipur, 2015). In an agriculture-dominated country like India instability of commodity prices has always been a major concern for farmers. There are various ways to cope with this problem. Apart from increasing the stability of the market by direct government intervention, various factors in the farm sector can better manage their activities. (Combe, 1997).

\section{Data base and Methodology}

The study was carried out in Northern Hill Zone of Chhattisgarh. A multi-stage random sampling design was adopted for the ultimate selection of potato growers. Two districts namely Surguja, and Balrampur were selected purposively on the basis of maximum area and production of potato crop. Out of these districts, one block namely Mainpat from Surguja and Kusmi from Balrampur were selected. Further, eleven villages from selected blocks were selected. Finally, a sample of 100 potato growers were selected with the help of probability proportion criteria. Thus, the sample consisted of 40 marginal, 32 small, 17 medium and 11 large farmers. To study the economics of potato production, the tabular analysis was employed to estimate disposal pattern of potato. The standard cost concepts approach was used to study the costs and returns from potato production. To work out cost of cultivation standard method of cost of cultivation employed by Commission for Agricultural Costs and Prices (CACP), Directorate of Economics and Statistics, Government of India was adopted.

\section{Details of CACP Cost concepts}

The cost concepts approach to farm costing is widely used in India. To work out the cost of cultivation, standard method of cost of cultivation employed by Commission for Agricultural Costs and Prices (CACP), Directorate of Economics and Statistics, Government of India was adopted. These include Cost A1, Cost A2, Cost B1, Cost B2, Cost C1, Cost $\mathrm{C} 2$ and Cost C3. Various costs have been worked out by applying following method:

Cost A1 = All actual expenses in cash and kind incurred in production. Cost A1: Consists of following 14 items of costs:

1. Value of hired human labour (permanent \& casual)

2. Value of owned bullock labour

3. Value of hired bullock labour

4. Value of owned machinery labour

5. Hired machinery charges

6. Value of fertilizers

7. Value of manure (produced on farm and purchased)

8. Value of seed (both farm-produced and purchased)

9. Value of insecticides, pesticide and fungicides.

10. Irrigation charges (both of the owned \& owned and hired tube wells, pumping sets etc.)

11. Canal-water charges

12. Land revenue, cesses and other taxes

13. Depreciation on farm implements (both bullock drawn \& worked with human labour, farm building and farm machinery).

14. Interest on the working capital.

Cost A2 = Cost A1+ Rent paid for Leased in Land Cost $\mathrm{B} 1=$ Cost $\mathrm{A} 1+$ Interest on value of owned fixed capital assets (excluding land)

Cost $\mathrm{B} 2=$ Cost $\mathrm{B} 1+$ rental value of owned land $(\mathrm{Net}$ of land revenue)

Cost $\mathrm{C} 1=$ Cost $\mathrm{B} 1+$ Imputed value of family labour.

Cost C2 $=$ Cost B2+Imputed value of family labour.

Cost C3 $=$ Cost C2 $+10 \%$ of Cost C2 on account of managerial function performed by farmer. 


\section{RESULTS AND DISCUSSION}

\section{Costs and returns from potato production}

The cost of potato cultivation across various operation land holdings categories has been presented in Table 1. As perusal the table 1 indicated that overall cost of cultivation of potato per hectare cost was found to be ₹ 47408.91 which was highest for large ( $₹ 52163.03)$ farmers followed by medium (₹ 48927.75), small (₹ 45537.95) and (₹ 43006.91) marginal farmers. Cost of cultivation showed increasing trend from marginal to large farmers. It is due to the fact that large farmers could incur more expenditure on modern farm inputs like quality seed, fertilizers, plant protection chemicals, hired labour and machinery etc.

The major item of cultivation of potato was total labour (36.39 per cent) followed by expenditure on seed (31.31 per cent), manure and fertilizer (14.58 per cent). The expenditure on hired human labour was the major cause for higher labour cost. The hired human labour cost accounted for 46.83 per cent. The overall expenditure on variable inputs was found to be ₹ 44240.75, which was found highest for large (₹ 48845.22) farmers followed by medium
(₹ 45722.33), small (₹ 42428.10) and marginal (₹ 39967.05) farmers. On an average, 93.32 per cent of total of total cost of cultivation was incurred on variable inputs. The expenditure on fixed inputs was estimated to be ₹ 3168.16 for all categories of farmers and account only 6.68 per cent of total cost of cultivation.

Keeping in view the high proportion of total labour cost there is a need to reduce the same by developing, promoting and incentivizing small scale machinery for potato cultivation. It was observed that the recommended dose of fertilizer was not applied in potato production there by resulting in reduced yield of potato. In view of this, it is imperative to educate and create awareness about the proper application of inputs in order to increase production and productivity of potato in the study area.

\section{Costs of potato production}

The costs of production has also been estimated and presented in Table 2. As perusal of table 2 indicated that overall cost of production of potato was found to be ₹ 625.56 which was highest for large farmer (₹ 631.24) and lowest for marginal (₹ 610.72). It was

Table 1: Costs of potato cultivation across various land holding categories (₹/ha)

\begin{tabular}{|c|c|c|c|c|c|c|}
\hline $\begin{array}{l}\text { Sl. } \\
\text { No. }\end{array}$ & Particulars/ Input cost & Marginal & Small & Medium & Large & Overall \\
\hline \multirow{2}{*}{1} & (a) Family labour & $6378.10(14.83)$ & $4263.26(9.36)$ & $2660.20(5.44)$ & $1465.98(2.81)$ & $3691.88(7.79)$ \\
\hline & (b) Hired labour & $4731.38(11.00)$ & $7022.44(15.42)$ & $9238.83(18.88)$ & $11322.66(21.71)$ & $8078.83(17.04)$ \\
\hline \multirow{2}{*}{2} & (c) Expenditure on bullock & $1454.99(3.38)$ & $897.05(1.97)$ & $422.60(0.86)$ & $103.79(0.20)$ & $719.61(1.52)$ \\
\hline & (d) Expenditure on Machine & $2833.09(6.59)$ & $4793.65(10.53)$ & $5380.41(11.00)$ & $6034.85(11.57)$ & $4760.50(10.04)$ \\
\hline 3 & Total labour cost & $15397.56(35.80)$ & $16976.40(37.28)$ & $17702.03(36.18)$ & $18927.27(36.28)$ & $17250.82(36.39)$ \\
\hline 4 & Seed & $14388.32(33.46)$ & $14601.62(32.06)$ & $14950.25(30.56)$ & $15426.80(29.57)$ & $14841.75(31.31)$ \\
\hline 5 & Plant protection & $2941.61(6.84)$ & $3390.70(7.45)$ & $4381.08(8.95)$ & $5123.71(9.82)$ & $3959.28(8.35)$ \\
\hline 6 & Manure and Fertilizer & $6090.75(14.16)$ & $6231.73(13.68)$ & $7369.07(15.06)$ & $7949.69(15.24)$ & $6910.31(14.58)$ \\
\hline 7 & Miscellaneous & $301.22(0.70)$ & $327.87(0.72)$ & $350.27(0.72)$ & $382.16(0 . .73)$ & $340.38(0.72)$ \\
\hline 8 & Interest on working capital & $847.59(1.97)$ & $899.78(1.98)$ & $969.64(1.98)$ & $1035.88(1.99)$ & $938.22(1.98)$ \\
\hline \multirow[t]{5}{*}{ A } & Total variable cost & 39967.05 (92.93) & $42428.10(93.17)$ & $45722.33(93.45)$ & $48845.52(93.64)$ & $44240.75(93.32)$ \\
\hline & Land revenue & $5.00(0.01)$ & $5.00(0.01)$ & $5.00(0.01)$ & $5.00(0.01)$ & $5.00(0.01)$ \\
\hline & Depreciation & $244.67(0.57)$ & $278.47(0.61)$ & $320.16(0.65)$ & $377.60(0.72)$ & $305.22(0.64)$ \\
\hline & Rental value on owned land & $2500.00(5.81)$ & $2500.00(5.49)$ & $2500.00(5.11)$ & $2500.00(4.79)$ & $2500.00(5.27)$ \\
\hline & Interest on fixed capital & $290.20(0.67)$ & $326.39(0.72)$ & $380.26(0.78)$ & $434.92(0.83)$ & $357.94(0.76)$ \\
\hline B & Total fixed cost & $3039.87(7.07)$ & $3109.85(6.83)$ & $3205.42(6.55)$ & $3317.51(6.36)$ & $3168.16(6.68)$ \\
\hline C & Total cost $(\mathrm{A}+\mathrm{B})$ & $43006.91(100)$ & $45537.95(100)$ & $48927.75(100)$ & $52163.03(100)$ & $47408.91(100)$ \\
\hline
\end{tabular}

Figures in parentheses indicate percentage to total. 
Table 2: Costs of potato production across various land holding categories (₹/qtl.)

\begin{tabular}{|c|c|c|c|c|c|c|}
\hline $\begin{array}{c}\text { Sl. } \\
\text { No. }\end{array}$ & Particulars & Marginal & Small & Medium & Large & Overall \\
\hline \multirow{2}{*}{1} & (a) Family labour & $90.57(14.83)$ & $57.96(9.36)$ & $34.32(5.44)$ & $18.02(2.81)$ & $50.22(8.03)$ \\
\hline & (b) Hired labour & $67.19(11.00)$ & $95.47(15.42)$ & $199.20(18.88)$ & $139.18(21.71)$ & $105.26(16.83)$ \\
\hline \multirow{2}{*}{2} & (c) Expenditure on bullock & $20.66(3.38)$ & $12.19(1.97)$ & $5.45(0.86)$ & $1.28(0.20)$ & $9.90(1.58)$ \\
\hline & (d) Expenditure on Machine & $40.23(6.59)$ & $65.17(10.53)$ & $69.42(11.00)$ & $74.18(11.57)$ & $62.25(9.95)$ \\
\hline 3 & Total labour cost & $218.65(35.80)$ & $230.78(37.28)$ & $228.38(36.18)$ & 232.66 (36.28) & $227.63(36.39)$ \\
\hline 4 & Seed & $204.32(33.46)$ & $198.50(32.06)$ & $192.88(30.56)$ & $189.63(29.57)$ & $196.33(31.39)$ \\
\hline 5 & Plant protection & $41.77(6.84)$ & $46.09(7.45)$ & $56.52(8.95)$ & $62.98(9.82)$ & $51.84(8.29)$ \\
\hline 6 & Manure and Fertilizer & 86.49 (14.16) & $84.72(13.68)$ & $95.07(15.06)$ & $97.72(15.24)$ & $91.00(14.55)$ \\
\hline 7 & Miscellaneous & $4.28(0.70)$ & $4.46(0.72)$ & $4.52(0.72)$ & $4.70(0.73)$ & $4.49(0.72)$ \\
\hline 8 & Interest on working capital & $12.04(1.97)$ & $12.23(1.98)$ & $12.51(1.98)$ & $12.73(1.99)$ & $12.38(1.98)$ \\
\hline \multirow[t]{5}{*}{ A } & Total variable cost & $567.55(92.93)$ & $576.78(93.17)$ & $589.89(93.45)$ & $600.44(93.64)$ & $583.67(93.30)$ \\
\hline & Land revenue & $0.07(0.01)$ & $0.07(0.01)$ & $0.06(0.01)$ & $0.06(0.01)$ & $0.007(0.01)$ \\
\hline & Depreciation & $3.47(0.57)$ & $3.79(0.61)$ & $4.13(0.65)$ & $4.64(0.72)$ & $4.01(0.64)$ \\
\hline & Rental value on owned land & $35.50(5.81)$ & $33.99(5.49)$ & $32.25(5.11)$ & $30.73(4.79)$ & $33.12(5.29)$ \\
\hline & Interest on fixed capital & $4.12(0.67)$ & $4.44(0.72)$ & $4.91(0.78)$ & $5.35(0.83)$ & $4.70(0.75)$ \\
\hline B & Total fixed cost & $43.17(7.07)$ & $42.28(6.83)$ & $4.91(6.55)$ & $40.78(6.36)$ & $41.96(6.70)$ \\
\hline $\mathrm{C}$ & Total cost $(\mathrm{A}+\mathrm{B})$ & $610.72(100)$ & $619.06(100)$ & $631.24(100)$ & $641.22(100)$ & $625.56(100)$ \\
\hline
\end{tabular}

Figures in parentheses indicate percentage to the total.

Table 3: Cost of cultivation as per the CACP approach (₹/ha.)

\begin{tabular}{ccccccc}
\hline S1. No. & Costs/Category & Marginal & Small & Medium & Large & Over-all \\
\hline 1 & Cost A1 & $33838.61(71.53)$ & $38448.31(76.76)$ & $43387.3(80.61)$ & $47762.13(83.24)$ & $40859.09(78.35)$ \\
2 & Cost A2 & $33838.61(71.53)$ & $38448.31(76.76)$ & $43387.3(80.61)$ & $47762.13(83.24)$ & $40859.09(78.35)$ \\
3 & Cost B1 & $34128.81(72.14)$ & $38774.69(77.41)$ & $43767.56(81.32)$ & $48197.05(84.00)$ & $41217.03(79.04)$ \\
4 & Cost B2 & $36628.81(77.43)$ & $41274.69(82.40)$ & $46267.56(85.97)$ & $50697.05(88.35)$ & $43717.03(83.83)$ \\
5 & Cost C1 & $40506.91(85.62)$ & $43037.95(85.92)$ & $46427.75(86.26)$ & $49663.03(86.55)$ & $44908.91(86.12)$ \\
6 & Cost C2 & $43006.91(90.91)$ & $45537.95(90.91)$ & $48927.75(90.91)$ & $52163.03(90.91)$ & $47408.91(90.91)$ \\
7 & Cost C3 & $47307.6(100)$ & $50091.75(100)$ & $53820.53(100)$ & $57379.33(100)$ & $52149.8(100)$ \\
\hline
\end{tabular}

Figures in parentheses indicate percentage to the total.

also observed from table that the cost of producing one quintal of potato increased with the increase in size of holdings. For producing a quintal of output 36.39 per cent of total cost was accounted by labour. The expenditure on variable inputs was found to be ₹ 583.67 accounting 93.30 per cent. The expenditure on fixed inputs was ₹ 41.96 only which accounted 6.70 per cent of total cost.

\section{Costs as per the CACP classification}

The various cost concepts used by CACP have been presented in Table 3. As perusal of table 3 indicated that overall, cost $\mathrm{A}_{1}$ accounted 78.35 per cent of total costs $\left(\operatorname{Cost} C_{3}\right.$. The cost $A_{1}$ and cost $A_{2}$ were found to be same as there was no land was taken on lease.
The cost $\mathrm{B}_{1}, \operatorname{cost} \mathrm{B}_{2^{\prime}}$ cost $\mathrm{C}_{1}$ and $\operatorname{cost} \mathrm{C}_{2}$ was found to be $79.04,83.83,86.12$ and 90.91 per cent of cost $\mathrm{C}_{3^{\prime}}$ respectively. The cost $\mathrm{C}_{3}$ which take into account the managerial function performed by farmers was ₹ 52149.80. All costs were comparatively higher for large farm followed by medium, small and marginal farmers. It shows that capital spending on production increased with increase in the farm size. This was because the large farmers purchased qualitative inputs in each and every season which were required for production of potato and also income source at large farms enabled them to purchase costlier inputs and hiring the labour for performing different activities in potato cultivation. 


\section{Returns from potato production}

The yield and value of output per hectare for the sampled household have been shown in table 4 . Overall yield per hectare of potato came to 75.71 quintals. It was observed that highest yield was accrued to the large farmers (81.35 qtl.) followed by medium (77.51 qtl.), small (73.56 qtl.) and marginal (70.42 qtl.) farmers. As it is clear from table that yield of potato increased with the size of holdings. This increases may occurred due to the fact that larger holdings enables farmers to use qualitative inputs in more efficient way than farmers with small holdings.

The overall value of output per hectare came to ₹ 92766.47, which was highest for large farmers (₹ 104275.24) and lowest for marginal farmers (79873.89). The overall net returns was found to be ₹ 45357.83. The net returns was highest for large farmers (₹ 52112.21) followed by medium (₹ 47993.85), small (₹ 44458.30) and marginal (₹ 36866.98). The overall input output ratio was found to be 1:1.96 which was highest for large (1:2) farmers followed by medium (1:1.98) and small (1:1.98) and marginal (1:1.86) farmers. The higher value of output on large farmers was associated with higher expenditure on modern farm inputs.

\section{Income over different costs}

The incomes over different costs were also worked out and shown in Table 5. The overall per hectare income over Cost- $\mathrm{A}_{1^{\prime}}$ Cost- $\mathrm{A}_{2^{\prime}}, \operatorname{Cost}-\mathrm{B}_{1^{\prime}}$ Cost- $\mathrm{B}_{2^{\prime}}$ Cost $-C_{1}$, Cost $-C_{2}$ and Cost- $C_{3}$ was estimated to be ₹ 51907.66, ₹ 51907.66, ₹ 51549.72, ₹ 49049.72, ₹ 47857.83, ₹ 45357.83 and ₹ 40616.94 respectively. The returns over various costs have been shown similar pattern as in case of cost i.e. income over various cost increases with increase in the size of land holding. Large farmers received higher income over all the cost than other categories of farmers.

\section{Marketed surplus and disposal pattern of potato}

As the table 6 showed the average yield (62.75 $\mathrm{qtl} /$ farm) of potato was found highest (145.62) for large farmers followed by medium (58.91 qtl/farm), small (33.10 qtl/farm) and marginal (13.38 qtl/farm) farmers. The marketable surplus accounted for 97.37 per cent of total output. The marketable surplus was highest for large (97.79 per cent) farmers and was lowest for marginal (95.74 per cent) farmers. It could be observed from table 4.11 that the marketable surplus was more than 95 per cent for all categories of farmers as potato is a cash crop.

Table 4: Returns from potato production for different categories of farmers

\begin{tabular}{|c|c|c|c|c|c|c|}
\hline Sl. No. & Particular & Marginal & Small & Medium & Large & Overall \\
\hline 1 & Average yield (qtl./ha.) & 70.42 & 73.56 & 77.51 & 81.35 & 75.71 \\
\hline 2 & Average price (₹/qtl.) & 1134.25 & 1223.44 & 1250.44 & 1281.81 & 1222.49 \\
\hline 3 & Gross returns (₹/ha.) & 79873.89 & 89996.25 & 96921.60 & 104275.24 & 92766.74 \\
\hline 4 & Cost of cultivation (₹/ha.) & 43006.91 & 45537.95 & 48927.75 & 52163.03 & 47408.91 \\
\hline 5 & Net returns (₹/ha.) & 36866.98 & 44458.30 & 47993.85 & 52112.21 & 45357.83 \\
\hline 6 & Cost of production (₹/qtl.) & 610.72 & 619.06 & 631.24 & 641.22 & 625.56 \\
\hline 7 & Input output ratio & 1:1.86 & 1:1.98 & 1:1.98 & $1: 2.00$ & 1:1.96 \\
\hline
\end{tabular}

Table 5: Income over different costs for different categories ( $/ / h a$.

\begin{tabular}{clccccc}
\hline S1. No. & Costs/Category & Marginal & Small & Medium & Large & Over-all \\
\hline 1 & Income over Cost A1 & 46035.27 & 51547.94 & 53534.31 & 56513.11 & 51907.66 \\
2 & Income over Cost A2 & 46035.27 & 51547.94 & 53534.31 & 56513.11 & 51907.66 \\
3 & Income over Cost B1 & 45745.08 & 51221.55 & 53154.05 & 56078.19 & 51549.72 \\
4 & Income over Cost B2 & 43245.08 & 48721.55 & 50654.05 & 53578.19 & 49049.72 \\
5 & Income over Cost C1 & 39366.97 & 46958.29 & 50493.85 & 54612.21 & 47857.83 \\
6 & Income over Cost C2 & 36866.97 & 44458.29 & 47993.85 & 52112.21 & 45357.83 \\
7 & Income over Cost C3 & 32566.28 & 39904.5 & 43101.08 & 46895.91 & 40616.94 \\
8 & Gross return & 79873.89 & 89996.25 & 96921.6 & 104275.2 & 92766.74 \\
\hline
\end{tabular}


Table 6: Marketed surplus of potato across various land holding categories (qtl./farm)

\begin{tabular}{|c|c|c|c|c|c|c|}
\hline S1. No. & Particular & Marginal & Small & Medium & Large & Overall \\
\hline 1 & Total quantity produces & $13.38(100)$ & $33.10(100)$ & $58.91(100)$ & $145.62(100)$ & $62.75(100)$ \\
\hline 2 & Quantity used for Consumption & $0.57(4.26)$ & $1.16(3.51)$ & $1.67(2.84)$ & $3.22(2.21)$ & $1.65(2.63)$ \\
\hline 3 & Marketable surplus & $12.81(95.74)$ & $31.94(96.49)$ & $57.24(97.16)$ & $142.39(97.79)$ & $61.10(97.37)$ \\
\hline
\end{tabular}

Figures in parentheses indicate percentage to total.

Table 7: Disposable Pattern of potato by various land holding categories (qtl./farm)

\begin{tabular}{clccccc}
\hline Sl. No. & Particular & Marginal & Small & Medium & Large & Overall \\
\hline 1 & Marketable Surplus & $12.81(100)$ & $31.94(100)$ & $57.24(100)$ & $142.39(100)$ & $61.10(100)$ \\
2 & Village trader & $2.93(22.87)$ & $4.34(13.60)$ & $0(0.00)$ & $0(0.00)$ & $1.82(2.98)$ \\
3 & Wholesaler & $6.01(46.93)$ & $18.23(57.07)$ & $45.09(78.78)$ & $140.73(98.83)$ & $52.52(85.96)$ \\
4 & Retailer & $3.77(29.46)$ & $9.06(28.37)$ & $11.57(20.22)$ & $0(0.00)$ & $6.1(9.98)$ \\
5 & Consumer & $0.10(0.74)$ & $0.31(0.96)$ & $0.57(1.00)$ & $1.66(1.17)$ & $0.66(1.08)$ \\
\hline
\end{tabular}

Figures in parentheses indicate percentage to total.

Only 2.63 per cent of total production was used for home consumption.

It could be observed from table 7 . Out of total marketable surplus, highest quantity (85.96 per cent) was marketed through wholesaler followed retailer (9.98 per cent) and village trader (2.98 per cent). Only 1.08 per cent was marketed directly to the consumers.

\section{CONCLUSION}

Growing potato is essentially a profitable economic activity. However, farmers often fail to realize profitable price primarily due to inadequate formal marketing facilities and lack of collateral credit availabilities from formal sources. Average cost of potato cultivation is $₹ 47408.91$ per ha, average gross income is ₹ 92766.74 per ha and average net income is ₹ 45357.83 per ha. The probable reason for higher expenditure on cultivation of potato crop is due to higher cost of potato seed, manure and fertilizer and expensive labour. The net income from the crop may be increased if they get remunerative prices of their produce and this is possible only if they get higher share in the market price of their produce. The overall marketable surplus of potato crop was found to be 97.37 per cent. Out of this 2.98 per cent were marketed through village trader, 85.96 per cent were marketed through wholesaler, 9.98 were marketed through retailer and remaining amount 1.08 per cent were marketed through consumer directly. The farmers in the study area need to be educated about the effect of timely and adequate application of fertilizers to increase the profitability of potato. A stable marketing infrastructure is needed to ensure the quick disposal of potato at remunerative prices.

\section{ACKNOWLEDGEMENTS}

The authors are very thankful to the Head, Department of Agricultural Economics, Indira Gandhi Krishi Vishwavidyalaya, Raipur for their guidance and support during research work without which this research could not be completed.

\section{REFERENCES}

Anonymous. 2015. Department of Horticulture, Government of Chhattisgarh, Raipur.

Anonymous. 2008. Food and Agriculture Organization. (http://www.fao.org/3/a-i1127e.pdf)

Anonymous. 2014. Food and Agriculture Organization. (http://www.potatopro.com/world/potato-statistics)

Anonymous. 2016. National Horticulture Research and Development Foundation. (http://nhrdf.org/pdf/potato \%20crop\%20report-\%2008\%20april\%202016.pdf)

Combe, M.O. 1997. The role of farmers' association in commodity price risk management and collateralized commodity finance. UNCTAD, Geneva.

Durgawati, W., Rajput, A.M. and Saraf, G.P. 2005. Economic analysis of potato and onion in Malwa region of Madhya Pradesh. Indian Journal of Economics and Development, 38(3): 7779.

Lal, H. and Sharma, K.D. 2006. Economics of potato production in Lahaul Valley, Himachal Pradesh. Journal of the Indian Potato Association, 33(3-4): 139-143. 
Noonari, S., Hakimzadi, W., Noor, I. and Ahmed, F. 2016. Economic analysis of potato production in sindh Pakistan. Journal of Biology, Agriculture and Healthcare, 6(5): 100-107.

Peer, Q.A., Ahmad, N., Kaur, J., Chesti, M.H., Ahman, H.S., Bhat, A. and Bhat, B.A. 2013. Study on economics of potato growing towards livelihood security in Jammu division, India. African Journal of Agricultural Research, 8(45): 5639-5644.

Rajput, A.M., Verma, A.R. and Jain, S.K. 2003. Relative profitability of potato varieties in Indore district of Madhya Pradesh. Agricultural Research New Series, 24(2): 437-439.

Sahadevan, K.G. 2007. Advantages of Commodity Futures Trading Through Electronic Trading Platform for Farmers of Uttar Pradesh: A Study of Potato and Mentha, Multi Commodity Exchange of India Limited, Mumbai.
Scott, G.J. and Suarez, V. 2012. The rise of Asia as the centre of global potato production and some implications for industry. Potato J., 39(3- 4):1-22.

Verma, A.R. and Rajput, A.M. 2002. Economics of production and marketing of potato in Indore district of Madhya Pradesh. Indian Journal of Agricultural Marketing, 14(2): 23-30.

Woolfe, J.A. 1987. The Potato in the human diet. New York: Cambridge University Press, pp. 10. 
